\title{
\begin{tabular}{l|l} 
Mitraries & DSpace@MIT
\end{tabular}
}

\author{
MIT Open Access Articles
}

\section{The Interannual Variability of Tropical Precipitation and Interhemispheric Energy Transport}

The MIT Faculty has made this article openly available. Please share how this access benefits you. Your story matters.

Citation: Donohoe, Aaron, John Marshall, David Ferreira, Kyle Armour, and David McGee. “The Interannual Variability of Tropical Precipitation and Interhemispheric Energy Transport." J. Climate 27, no. 9 (May 2014): 3377-3392. (c) 2014 American Meteorological Society.

As Published: http://dx.doi.org/10.1175/JCLI-D-13-00499.1

Publisher: American Meteorological Society

Persistent URL: http://hdl.handle.net/1721.1/91980

Version: Final published version: final published article, as it appeared in a journal, conference proceedings, or other formally published context

Terms of Use: Article is made available in accordance with the publisher's policy and may be subject to US copyright law. Please refer to the publisher's site for terms of use. 


\title{
The Interannual Variability of Tropical Precipitation and Interhemispheric Energy Transport
}

\author{
AARON DONOHOE \\ Massachusetts Institute of Technology, Cambridge, Massachusetts \\ JOHN MARSHALL \\ Massachusetts Institute of Technology, Cambridge, Massachusetts \\ DAVID FERREIRA \\ Massachusetts Institute of Technology, Cambridge, Massachusetts, and University of Reading, Reading, United Kingdom \\ KyLE ARMOUR AND DAVID MCGEe \\ Massachusetts Institute of Technology, Cambridge, Massachusetts
}

(Manuscript received 19 August 2013, in final form 16 January 2014)

\begin{abstract}
The interannual variability of the location of the intertropical convergence zone (ITCZ) is strongly $(R=0.75)$ correlated with the atmospheric heat transport across the equator ( $\mathrm{AHT}_{\mathrm{EQ}}$ ) over the satellite era (1979-2009). A $1^{\circ}$ northward displacement of the ITCZ is associated with $0.34 \mathrm{PW}$ of anomalous $\mathrm{AHT}_{\mathrm{EQ}}$ from north to south. The $\mathrm{AHT}_{\mathrm{EQ}}$ and precipitation anomalies are both associated with an intensification of the climatological Hadley cell that is displaced north of the equator. This relationship suggests that the tropical precipitation variability is driven by a hemispheric asymmetry of energy input to the atmosphere at all latitudes by way of the constraint that $\mathrm{AHT}_{\mathrm{EQ}}$ is balanced by a hemispheric asymmetry in energy input to the atmosphere.

A 500-yr coupled model simulation also features strong interannual correlations between the ITCZ location and $\mathrm{AHT}_{\mathrm{EQ}}$. The interannual variability of $\mathrm{AHT}_{\mathrm{EQ}}$ in the model is associated with a hemispheric asymmetry in the top of the atmosphere radiative anomalies in the tropics with the Northern Hemisphere gaining energy when the ITCZ is displaced northward. The surface heat fluxes make a secondary contribution to the interannual variability of $\mathrm{AHT}_{\mathrm{EQ}}$ despite the fact that the interannual variability of the ocean heat transport across the equator $\left(\mathrm{OHT}_{\mathrm{EQ}}\right)$ is comparable in magnitude to that in $\mathrm{AHT}_{\mathrm{EQ}}$. The $\mathrm{OHT}_{\mathrm{EQ}}$ makes a minimal impact on the atmospheric energy budget because the vast majority of the interannual variability in $\mathrm{OHT}_{\mathrm{EQ}}$ is stored in the subsurface ocean and, thus, the interannual variability of $\mathrm{OHT}_{\mathrm{EQ}}$ does not strongly impact the atmospheric circulation.
\end{abstract}

\section{Introduction}

The region of intense tropical precipitation, known as the intertropical convergence zone (ITCZ), is collocated with the ascending branch of the Hadley cell (Hadley 1735). The atmospheric heat transport in the deep tropics is dominated by the mean overturning

Corresponding author address: Aaron Donohoe, Dept. of Earth, Atmospheric and Planetary Sciences, Massachusetts Institute of Technology, Room 54-918, 77 Massachusetts Avenue, Cambridge, MA 02139-4307.

E-mail: thedhoe@mit.edu circulation, with net heat transport oriented in the direction of motion in the upper branch of the Hadley cell (Held 2001). Therefore, energy is transported away from the ITCZ. Consequently, an ITCZ in the Southern Hemisphere (SH) implies northward atmospheric energy transport across the equator $\left(\mathrm{AHT}_{\mathrm{EO}}\right)$, and an ITCZ in the Northern Hemisphere $(\mathrm{NH})$ requires southward $\mathrm{AHT}_{\mathrm{EQ}}$ (Frierson and Hwang 2012).

The close connection between ITCZ location and $\mathrm{AHT}_{\mathrm{EQ}}$ has been well documented in the recent literature across a myriad of time scales and applications ranging from idealized model simulations to the 
observational data. Zhang and Delworth (2005) found that freshwater hosing in the North Atlantic resulted in a shutdown of the Atlantic meridional overturning circulation, cooling the $\mathrm{NH}$, and shifting the ITCZ to the south. They related the ITCZ shift to the enhanced northward $\mathrm{AHT}_{\mathrm{EQ}}$ demanded by the system as the northward ocean heat transport was reduced. Similarly, Yoshimori and Broccoli (2008, 2009), Kang et al. (2008), and Chiang and Bitz (2005) found that a prescribed hemispheric asymmetry in forcing (i.e., surface fluxes and ice cover) resulted in an ITCZ shift toward the source of atmospheric heating in order to provide the necessary anomalous $\mathrm{AHT}_{\mathrm{EQ}}$ away from the heat source.

The climatological-mean ITCZ location can be related to the hemispheric asymmetry of energy input into the atmosphere, driven by hemispheric asymmetries in energy fluxes at both the top of the atmosphere (TOA) and at the ocean surface. The resulting $\mathrm{AHT}_{\mathrm{EQ}}$ requires that the ITCZ be located in the hemisphere in which the atmosphere is heated more strongly (Frierson et al. 2013) and the displacement of the ITCZ from the equator is proportional to the magnitude of the hemispheric asymmetry in atmospheric heating (Donohoe et al. 2013). Using this framework, Frierson et al. (2013) and Marshall et al. (2014) recently demonstrated that the observed annual-mean ITCZ location (to the north of the equator) is a consequence of northward ocean heat transport across the equator and largely compensating southward $\mathrm{AHT}_{\mathrm{EQ}}$ demanded by nearly hemispherically symmetric net radiation at the TOA. Moreover, Frierson and Hwang (2012) found that the response of the ITCZ to the anthropogenic forcing varies drastically between different global climate models and is strongly correlated with the $\mathrm{AHT}_{\mathrm{EQ}}$ change demanded by the hemispheric asymmetry in extratropical radiative feedbacks. In this view, the annual-mean spatial distribution of tropical precipitation is fundamentally set by the large-scale oceanic circulations (that give rise to the cross-equatorial oceanic energy transport) and the hemispheric asymmetry in TOA energy fluxes.

A quantitative relationship between the ITCZ location and $\mathrm{AHT}_{\mathrm{EQ}}$ of $3^{\circ}$ latitude per petawatt was established by Donohoe et al. (2013); this scaling was found to apply to the seasonal cycle in the observations, the seasonal cycle in coupled climate models, and the shift in the annual-mean ITCZ location due to the anthropogenic and paleoclimate forcing. Seasonal variations in $\mathrm{AHT}_{\mathrm{EQ}}$ (and therefore the ITCZ location) are driven by seasonal variations in insolation and opposed by ocean heat storage and emitted radiation at the TOA (Donohoe and Battisti 2013). On seasonal time scales, ocean heat transport and atmospheric energy storage make a negligible contribution to the hemispheric asymmetry of atmospheric heating when compared with the contributions from TOA radiation and ocean energy storage. This is in contrast to the annual-mean climatology where ocean heat transport plays a fundamental role in sustaining the mean position of the ITCZ.

Here, we consider the relationship between interannual variability in ITCZ location and $\mathrm{AHT}_{\mathrm{EQ}}$ with a focus on the interannual frequency (period of $2 \rightarrow 10 \mathrm{yr}$ ) variability. We first quantify this relationship within the observational record and compare it to the scaling identified previously within the contexts of the seasonal cycle and the equilibrium response to a climate perturbation. We then assess the roles of several candidate mechanisms for driving the interannual variability of $\mathrm{AHT}_{\mathrm{EQ}}$. As summarized above, in the long-term mean $\mathrm{AHT}_{\mathrm{EQ}}$ (and thus the ITCZ location) is driven primarily by the hemispheric asymmetry of surface heat fluxes via the cross-equatorial ocean heat transport, while over the seasonal cycle it is driven by radiative fluxes at the TOA. A key question is, are anomalies in surface heat fluxes or TOA radiative fluxes responsible for the interannual variability of $\mathrm{AHT}_{\mathrm{EQ}}$ and ITCZ location? Alternatively, are other mechanisms - such as tropical TOA radiative anomalies associated with the shifting Hadley cell itself-of central importance? Distinguishing between these candidate mechanisms for driving interannual variability in $\mathrm{AHT}_{\mathrm{EQ}}$ is difficult in the observational record due to the large uncertainties in estimates of TOA radiation and surface heat fluxes, neither of which are directly observed by a consistent observational network over a prolonged time period (Trenberth and Caron 2001). For this reason, we turn to a coupled atmosphere-ocean general circulation model simulation that also exhibits a strong correlation between ITCZ location and $\mathrm{AHT}_{\mathrm{EQ}}$ to diagnose the cause of their respective interannual variabilities.

Our manuscript is organized as follows: In section 2, we analyze the observed interannual variability of the ITCZ location and $\mathrm{AHT}_{\mathrm{EQ}}$ and the associated anomalies in the tropical precipitation and the Hadley cell. We find that the ITCZ location and $\mathrm{AHT}_{\mathrm{EQ}}$ are strongly correlated over the observational record with a quantitative relationship similar to that identified previously in Donohoe et al. (2013) over seasonal and climatological time scales. We then diagnose a coupled model simulation performed with the Geophysical Fluid Dynamics Laboratory (GFDL)'s Climate Model, version 2.1 (CM2.1) (section 3). We demonstrate that the interannual variability of ITCZ location and $\mathrm{AHT}_{\mathrm{EQ}}$ are strongly correlated in the model (section $3 \mathrm{a}$ ), and we partition the interannual variability of $\mathrm{AHT}_{\mathrm{EQ}}$ between radiative anomalies at the TOA and surface heat flux anomalies (section $3 b$ ). We show that the interannual variability of $\mathrm{AHT}_{\mathrm{EQ}}$ is 
associated with a positive feedback between the ITCZ shift and the cloud radiative response in the tropics. Anomalies in the surface heat fluxes play a secondary role and are uncorrelated with anomalies in the ocean heat transport on decadal and shorter time scales. The latter result implies that the interannual to decadal oscillations in the Atlantic meridional overturning circulation (AMOC) and other ocean circulations do not significantly impact the large-scale tropical precipitation. Anomalies in ocean heat transport are largely compensated by energy storage at depth, away from the ocean surface, and thus do not drive corresponding anomalies in atmospheric heat transport at the decadal frequency (section 3c). A summary and conclusion follows.

\section{Observations}

In this section, we demonstrate that the interannual variability of ITCZ location is negatively correlated with $\mathrm{AHT}_{\mathrm{EQ}}$ over the satellite era of observations (1979-2009), where the sign of the correlation is defined such that the displacement of the ITCZ to the north is accompanied by anomalous $\mathrm{AHT}_{\mathrm{EQ}}$ to the south. The interannual northward migration of the zonal-mean ITCZ is primarily due to an amplification of the climatological maximum precipitation and is accompanied by an amplification of the climatological annual-mean Hadley circulation. The associated southward $\mathrm{AHT}_{\mathrm{EQ}}$ anomaly is due to the intensification of the counterclockwise rotating Hadley cell at the equator.

\section{a. Datasets and methods}

\section{1) PRecipitation AND ITCZ LOCATION}

We analyze monthly-mean precipitation data from the National Oceanic and Atmospheric Administration
(NOAA)'s Climate Prediction Center (CPC)'s merged analysis (Xie and Arkin 1996) over the period 19792009. This gridded dataset is derived from gauge measurements, satellite observations, and numerical models. The location of the ITCZ is defined as the precipitation centroid $\left(P_{\mathrm{CENT}}\right)$ as used by Frierson and Hwang (2012) and Donohoe et al. (2013). The term $P_{\text {CENT }}$ is defined as the median of the zonal average precipitation between $20^{\circ} \mathrm{S}$ and $20^{\circ} \mathrm{N}$. This definition of the ITCZ takes into account the spatial distribution of precipitation over the entire tropics: if the precipitation is strongly peaked (i.e., a delta function), $P_{\text {CENT }}$ is collocated with the precipitation maximum; if the precipitation is spatially invariant over the tropics, $P_{\text {CENT }}$ is on the equator; and if the precipitation is bimodal, $P_{\mathrm{CENT}}$ is a weighted average between the modes.

\section{2) ATMOSPHERIC HEAT TRANSPORT ACROSS THE EQUATOR}

The atmospheric heat transport is calculated from National Centers for Environmental Prediction (NCEP) reanalysis fields (Kalnay et al. 1996). We use the 4 times daily reanalysis with a (horizontal) spectral resolution of T62 and 17 vertical levels. The mass budget is balanced using a barotropic wind correction (Trenberth 1997) prior to the energy flux calculations. The atmospheric energy flux is calculated as the vertical integral of the meridional flux of moist static energy (MSE). ${ }^{1}$ This procedure is used to compose monthly averaged atmospheric heat transport from 1979 to 2009.

The atmospheric heat transport is decomposed into components associated with the time and zonal-mean circulation, stationary eddies, and transient eddies following Priestley (1949) and Lorenz (1953):

$$
\mathrm{AHT}=\frac{2 \pi a \cos \theta}{g} \int_{P_{S}}^{0} \underbrace{[\bar{V}][\overline{\mathrm{MSE}}]}_{\text {MOC }}+\underbrace{\overline{[V]^{\prime}[\mathrm{MSE}]^{\prime}}}_{\text {TOC }}+\underbrace{\left[\overline{V^{*}} \overline{\mathrm{MSE}^{*}}\right]}_{\text {Stat.eddy }}+\underbrace{\left[\overline{V^{* \prime} \mathrm{MSE}^{* \prime}}\right]}_{\text {Trans.eddy }} d P
$$

The $V$ is the meridional velocity. $\overline{\text { Overbars }}$ are time averages, [square brackets] are zonal averages, primes (') are departures from the time mean, and asterisks (*) are departures from the zonal average. The first term is the energy transport due to the time and zonal average meridional overturning circulation (MOC; i.e., the Hadley cell). The second term is the energy transport due to the temporal covariance of the zonal average overturning circulation and vertical stratification and will be referred as the transient overturning circulation (TOC). The time average vertical stratification ([$\overline{\mathrm{MSE}}]$ ) is two orders of magnitude larger than the temporal departures in the vertical stratification ([MSE] $\left.]^{\prime}\right)$. Therefore, the TOC energy transport is much smaller than that of the MOC, and the TOC will be

\footnotetext{
${ }^{1}$ Moist static energy is the sum of sensible, latent, and potential energy $\left(c_{p} T+L q+g Z\right)$.
} 

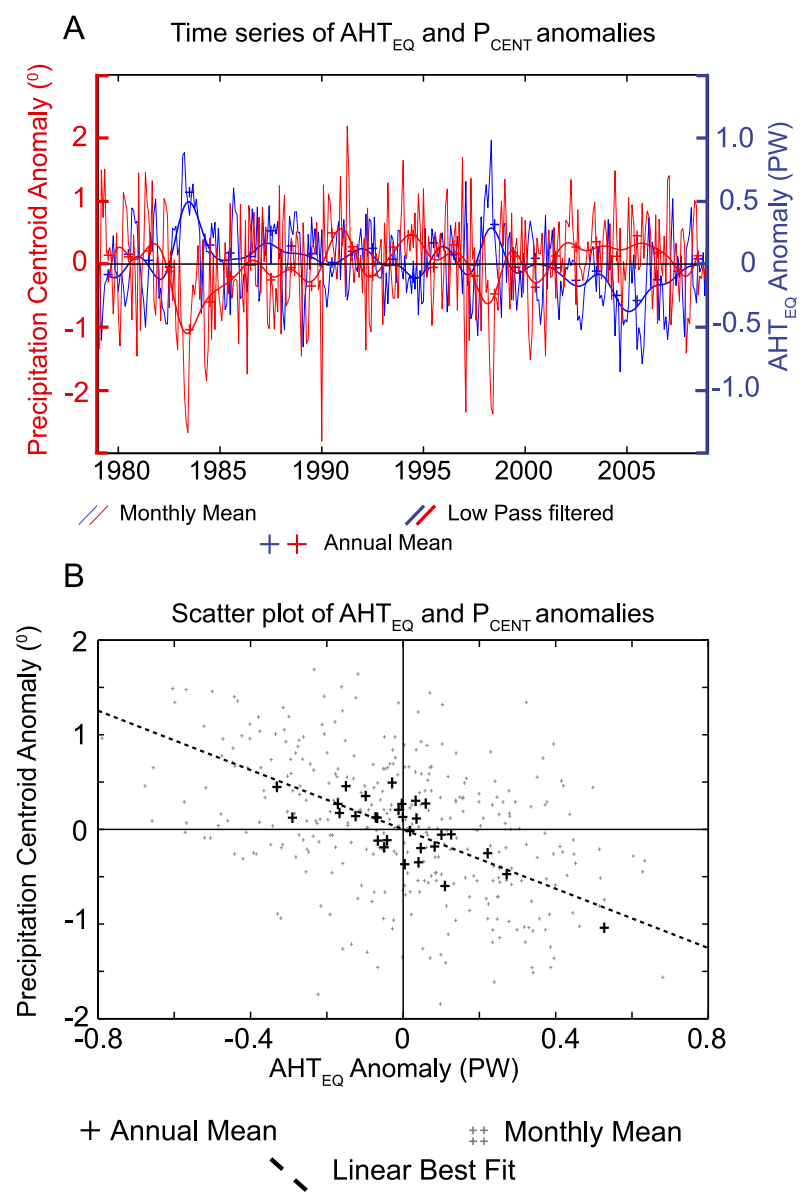

FIG. 1. (a) Time series of ITCZ location anomaly as measured by the $P_{\text {CENT }}$ (red) and the anomaly in atmospheric heat transport at the equator (blue). The thin lines are the monthly-mean anomalies, and the thick lines are the low-pass filtered time series (cutoff period of $2 \mathrm{yr}$ ). The thick crosses are the annual-mean anomalies from the climatology. (b) Scatterplot of the anomalies in $P_{\text {CENT }}$ and $\mathrm{AHT}_{\mathrm{EQ}}$. The small gray crosses are the monthly means, and the thick black crosses are the annual means. The dashed black line is the linear best fit to the annual-mean data.

included with the MOC for the remainder of this study. The third term is the stationary eddy energy transport. The fourth term is the transient eddy energy transport.

\section{b. Results}

The monthly anomalies in $P_{\mathrm{CENT}}$ have a standard deviation of $0.8^{\circ}$, while those in $\mathrm{AHT}_{\mathrm{EQ}}$ have a standard deviation $(\sigma)$ of $0.3 \mathrm{PW}$ (thin red and blue lines, respectively, in Fig. 1a). Monthly anomalies in $P_{\text {CENT }}$ and $\mathrm{AHT}_{\mathrm{EQ}}$ are significantly negatively correlated $(R=$ $-0.5)$ at the $99 \%$ confidence interval with a regression coefficient $(b)$ of $-1.5^{\circ} \pm 0.7^{\circ} \mathrm{PW}^{-1}$ (Fig. 1b), where the confidence interval is $95 \%$. Anomalies in $P_{\text {CENT }}$ and $\mathrm{AHT}_{\mathrm{EQ}}$ are more strongly correlated at lower frequencies; a portion of the high-frequency variability in tropical precipitation is not associated with changes in the Hadley cell and thus has no associated atmospheric heat transport anomaly. For this reason, we focus here on the variability of tropical precipitation and atmospheric heat transport at the interannual frequency. Low-pass filtering the monthly anomalies in $\mathrm{AHT}_{\mathrm{EQ}}$ and $P_{\mathrm{CENT}}$ with a 2 -yr period cutoff filter (thick lines in Fig. 1a) results in a correlation coefficient of -0.75 and a regression coefficient of $-1.6^{\circ} \pm 0.7^{\circ} \mathrm{PW}^{-1}$. The regression coefficient between interannual variations in $P_{\mathrm{CENT}}$ and $\mathrm{AHT}_{\mathrm{EQ}}$ is comparable in magnitude to that found over the climatological seasonal cycle $\left(-2.7^{\circ} \pm 0.6^{\circ} \mathrm{PW}^{-1}\right)$ and for the annual-mean ITCZ shift in perturbed climate states (Donohoe et al. 2013). This result suggests that the mutual dependence of $P_{\mathrm{CENT}}$ and $\mathrm{AHT}_{\mathrm{EQ}}$ on the Hadley cell location is nearly time scale independent, although the fundamental cause of the quantitative relationship is unclear; both the intensification of the Hadley cell as the ITCZ moves off the equator and the collocation of the ITCZ with the maximum upward velocity that is equatorward of the zero streamfunction cause the ITCZ to be less sensitive to extratropical forcing than would be the case if the Hadley cell simply translated meridionally (Donohoe et al. 2013). Statistically indistinguishable statistics (i.e., correlations, regression, and variance retained) between $\mathrm{AHT}_{\mathrm{EQ}}$ and $P_{\mathrm{CENT}}$ are found using the annual-mean values (red and blue crosses in Fig. 1a and thick black crosses in Fig. 1b). ${ }^{2}$ For the remainder of this study, we will consider statistics derived from the annual-mean data when discussing the interannual variability. We note that the annual-mean $P_{\mathrm{CENT}}$ and $\mathrm{AHT}_{\mathrm{EQ}}$ anomalies have standard deviations that are $44 \%$ and $55 \%$ of their monthly anomalies, respectively.

Applying Eq. (1), the interannual variability in $\mathrm{AHT}_{\mathrm{EQ}}$ is primarily $(72 \%)$ due to the anomalies in the MOC of the atmosphere (i.e., the Hadley cell). The interannual variability of $\mathrm{AHT}_{\mathrm{EQ}}$ associated with the stationary eddies and transient eddies are both approximately one order of magnitude smaller than the $\mathrm{AHT}_{\mathrm{EQ}}$ variability associated with the MOC. ${ }^{3}$ The precipitation anomaly associated with a $1^{\circ}$ northward

\footnotetext{
${ }^{2}$ This result suggests that the boxcar window filter of the annual mean does not adversely alias the time series of $\mathrm{AHT}_{\mathrm{EQ}}$ and $P_{\text {CENT }}$; aliasing would be most problematic if there was significant variability at periods of 8 and 4 months.

${ }^{3}$ The dominance of the MOC in the interannual variability of atmospheric energy transport is in contrast to the annual-mean climatology, where the MOC, stationary eddies, and transient eddies all make comparable contributions to $\mathrm{AHT}_{\mathrm{EQ}}$ (Marshall et al. 2014).
} 


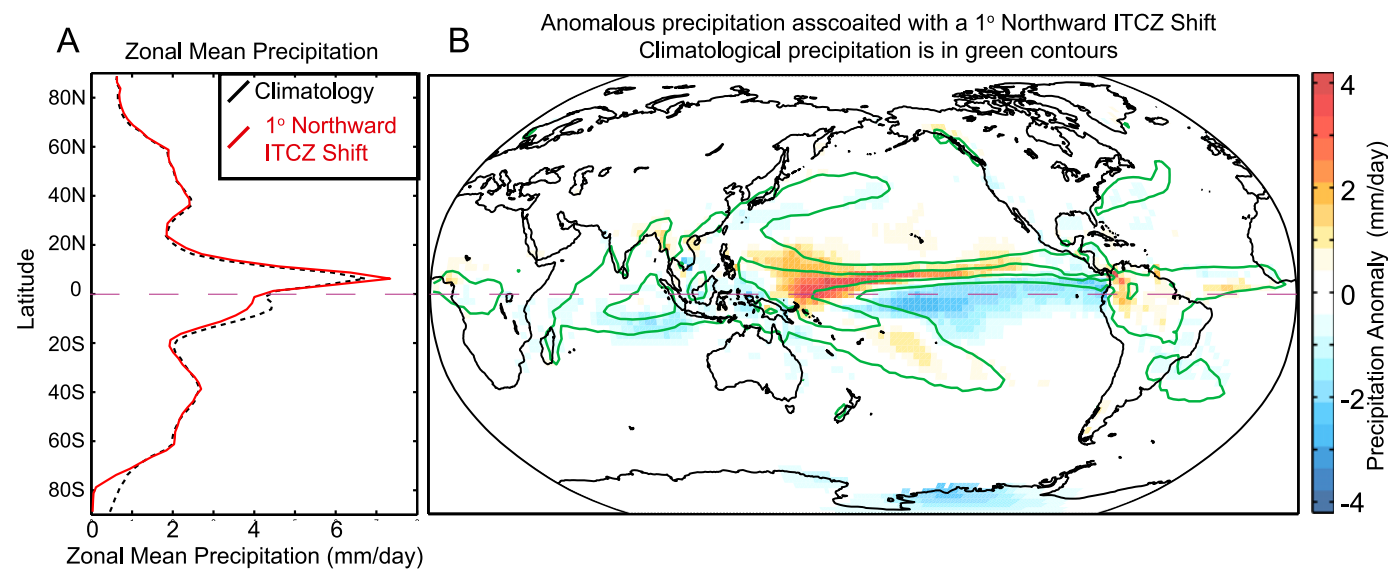

FIG. 2. (a) Zonal-mean precipitation climatology (dashed black line) and precipitation associated with a $1^{\circ}$ northward shift in ITCZ location (red) calculated from regressing the annual-mean $P_{\text {CENT }}$ anomaly onto the annualand zonal-mean precipitation anomaly. (b) Map of precipitation anomaly associated with a $1^{\circ}$ northward shift in zonal-mean $P_{\text {CENT }}$ evaluated from the interannual variability. The green contours are the climatological precipitation with a contour interval of $4 \mathrm{~mm} \mathrm{day}^{-1}$ (zero contour omitted). The dashed purple line is the equator.

ITCZ shift shows an intensification of the climatological precipitation maximum in the tropical Pacific, north of the equator, and decreases in precipitation on and south of the equator in the Pacific (Fig. 2). The streamfunction anomaly associated with a $1^{\circ}$ northward ITCZ shift (Fig. 3b) shows an intensified counterclockwise rotating cross-equatorial cell providing an anomalous energy transport (of $0.34 \mathrm{PW}$ ) ${ }^{4}$ from the $\mathrm{NH}$ to the $\mathrm{SH}$, primarily in the thermally direct streamfunction anomaly ( $0.24 \mathrm{PW}$ is associated with the Hadley cell anomaly, and the remainder is due to stationary eddies). The precipitation anomalies show enhanced precipitation in the region of anomalous upward motion in the Hadley cell and decreased precipitation in the region of enhanced subsidence. These results collectively suggest that the interannual variability of the ITCZ location and the atmospheric heat transport across the equator are primarily controlled by their mutual dependence on the Hadley cell. The interannual variability of the Hadley cell, tropical precipitation, and $\mathrm{AHT}_{\mathrm{EQ}}$ is best described as an intensification of the hemispherically asymmetric features, including the intensification of the precipitation maximum, cross-equatorial Hadley cell, and heat transport in the thermally direct MOC.

This observed interannual relationship between the $\mathrm{AHT}_{\mathrm{EQ}}$ and ITCZ location $\left(P_{\mathrm{CENT}}\right)$ can be compared to that in the climatological mean (Frierson et al. 2013;

\footnotetext{
${ }^{4}$ We note that the $0.34-\mathrm{PW} \mathrm{AHT}_{\mathrm{EQ}}$ anomaly associated with a $1^{\circ}$ ITCZ shift is not equal to the reciprocal of the regression coefficient between $P_{\mathrm{CENT}}$ and $\mathrm{AHT}_{\mathrm{EQ}}$ of $1.6^{\circ} \mathrm{PW}^{-1}$ because the variables are not perfectly correlated.
}

Marshall et al. 2014), wherein the ITCZ location, in the $\mathrm{NH}$, is accompanied by a southward $\mathrm{AHT}_{\mathrm{EQ}}$ of order $-0.2 \mathrm{PW}$ (Fig. 3a). This value of $\mathrm{AHT}_{\mathrm{EQ}}$ is a consequence of (i) ocean heat transport (of about $0.4 \mathrm{PW}$ ) northward across the equator and (ii) climatological radiative fluxes at the TOA that are nearly hemispherically symmetric in the shortwave (Voigt et al. 2013) but slightly asymmetric in the longwave (cooling the NH by $0.2 \mathrm{PW}$ ); combined, this results in the atmosphere being heated more strongly in the $\mathrm{NH}$ than in the $\mathrm{SH}$, setting the climatological annual-mean ITCZ position. The observed anomalies in the $\mathrm{AHT}_{\mathrm{EO}}$ and ITCZ location on interannual time scales (Fig. 3b) must similarly be associated with interhemispheric asymmetries in energy input to the atmosphere, through interhemispheric differences in radiative fluxes at the TOA or through surface heat flux anomalies due to the ocean heat transport and storage. Distinguishing the physical processes responsible for the interannual variability of the hemispheric atmospheric energy budget is an unresolved issue in climate dynamics. The observational record does not allow an accurate attribution of the $\mathrm{AHT}_{\mathrm{EO}}$ anomalies to anomalies in surface fluxes (ocean heat transport and storage) and radiative anomalies at the TOA due to the sparseness and lack of temporal continuity of the direct observations of the TOA radiative fluxes and surface energy fluxes; observational estimates of the TOA radiation [Clouds and the Earth's Radiant Energy System (CERES) Energy Balanced and Filled (EBAF); Loeb et al. 2009] are only available for the 2001-12 time period, which is insufficient to provide robust correlations between ITCZ location and energy fluxes (see conclusions section for additional discussion). Thus, we turn to model 


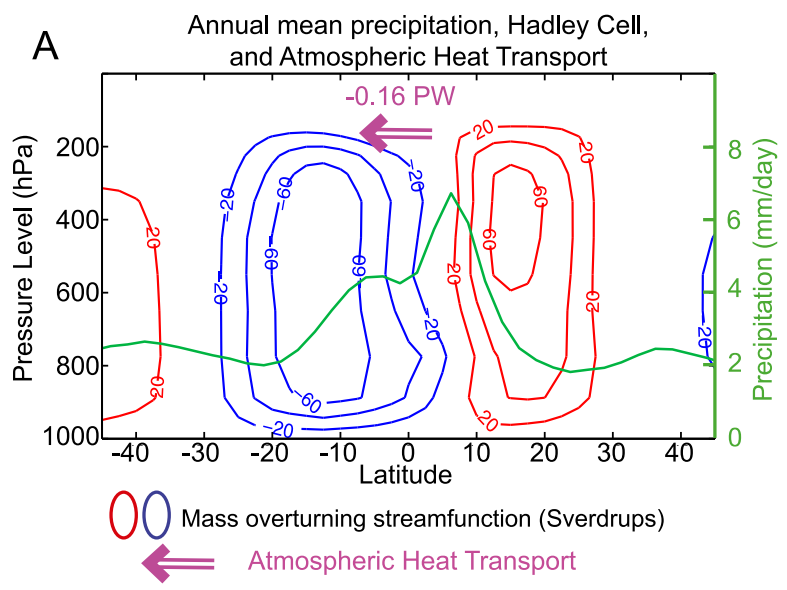

B Anomaly in precipitation, Hadley Cell and Atmospheric

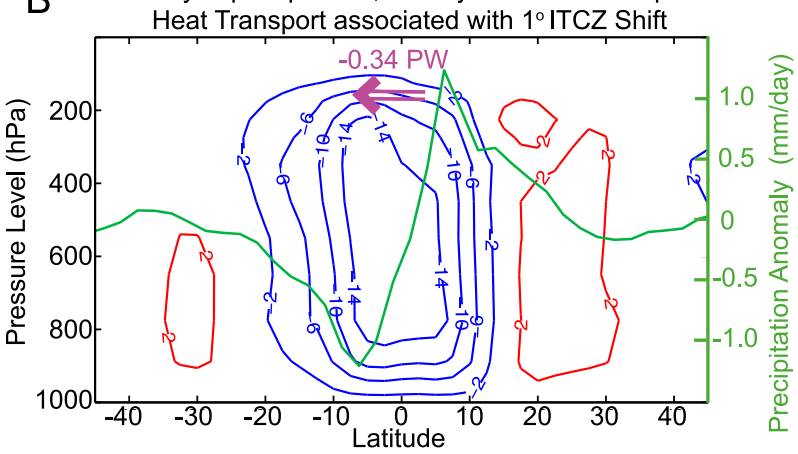

FIG. 3. (a) Climatological annual-mean streamfunction (contours) in Sv, coplotted with the zonal-mean precipitation (green, scale on the right axis). The $\mathrm{AHT}_{\mathrm{EQ}}$ is indicated in the pink arrow. (b) As in (a), but for the annual-mean anomalies associated with a $1^{\circ}$ northward ITCZ shift calculated from regression of interannual variability of $P_{\mathrm{CENT}}$ onto the streamfunction and precipitation.

simulations to ask what drives and determines the magnitude of the interannual variability of $\mathrm{AHT}_{\mathrm{EQ}}$ and ITCZ location.

\section{Coupled climate model}

Thus far we have demonstrated that the interannual variations in ITCZ location $\left(P_{\mathrm{CENT}}\right)$ are strongly negatively correlated with those in atmospheric energy transport across the equator $\left(\mathrm{AHT}_{\mathrm{EQ}}\right)$ over the observational record. Here, we show that the interannual variability of $P_{\mathrm{CENT}}$ and $\mathrm{AHT}_{\mathrm{EQ}}$ in a coupled climate model has similar negative correlations to those found in the observations. We then attribute the interannual variability of $\mathrm{AHT}_{\mathrm{EQ}}$ to anomalies in TOA radiation and surface fluxes related to ocean heat content changes and ocean heat transport anomalies.

We analyze a preindustrial simulation performed with the GFDL CM2.1 coupled model (Delworth et al. 2006). The atmospheric model features a finite volume dynamical core (Lin 2004) with a horizontal resolution of approximately $2^{\circ}$ latitude and 24 vertical levels. The ocean model is on a tripolar grid at a nominal resolution of $1^{\circ}$ (Griffies et al. 2005). The simulation is run for $500 \mathrm{yr}$ with greenhouse gas and aerosol concentrations fixed at preindustrial levels, and we perform our analysis over the last $450 \mathrm{yr}$.

\section{a. Interannual variability of ITCZ location and $A H T_{E Q}$}

The annual-mean anomalies of $P_{\mathrm{CENT}}$ and $\mathrm{AHT}_{\mathrm{EQ}}$ are strongly negatively correlated $(R=-0.76)$ with a regression coefficient of $3^{\circ} \mathrm{PW}^{-1}$ (thick crosses in Fig. 4). Similar (statistically indistinguishable) results are found when considering the low-pass filtered time series using a double-pass Butterworth filter with a cutoff period of $2 \mathrm{yr}$ (solid lines in Fig. 4a). The monthly variability of both $P_{\mathrm{CENT}}$ and $\mathrm{AHT}_{\mathrm{EQ}}$ is large relative to the interannual variability; less than $20 \%$ of the variability is at periods more than $1 \mathrm{yr}$. However, the monthly variations in $P_{\mathrm{CENT}}$ and $\mathrm{AHT}_{\mathrm{EQ}}$ are weakly correlated $(R=$ -0.39 ; thin gray crosses in Fig. $4 b$ ) compared to the interannual variability. Therefore, we will define the interannual variability of $P_{\mathrm{CENT}}$ and $\mathrm{AHT}_{\mathrm{EQ}}$ as the variance in the annual means, consistent with our analysis of the observations. We note that the correlation between $\mathrm{AHT}_{\mathrm{EQ}}$ and $P_{\mathrm{CENT}}$ is larger in magnitude $(R=-0.88)$ at the decadal frequency compared to interannual frequency, but that the variance in each is 5 times smaller at the decadal frequency.

The interannual variability of $P_{\mathrm{CENT}}$ in the GFDL model is primarily associated with a pulsing of the climatological precipitation maximum just north of the equator in the Pacific (not shown). The precipitation anomaly associated with a northward $P_{\mathrm{CENT}}$ anomaly also features a northward shift of precipitation maximum in the Indian Ocean and a very weak signal in the Atlantic basin. Overall, the interannual variability of $P_{\text {CENT }}$ shows a very similar spatial footprint to that found in the observations (Fig. 2). The interannual variability of $\mathrm{AHT}_{\mathrm{EQ}}$ is associated with a pulsing of the climatological annual-mean Hadley cell with a southward $\mathrm{AHT}_{\mathrm{EO}}$ anomaly corresponding to an intensification of the counterclockwise rotating cell at the equator (not shown). These results suggest that the interannual variability of $P_{\mathrm{CENT}}$ and $\mathrm{AHT} \mathrm{EQ}_{\mathrm{EQ}}$ in the GFDL model reflect the same mutual connection among atmospheric heat transport, tropical precipitation, and Hadley cell dynamics, as were identified in the observational record (Fig. 3).

\section{b. Energy fluxes contributing to the interannual variability of $A H T_{E Q}$}

The previous section demonstrated that the interannual variability of the tropical precipitation in the 

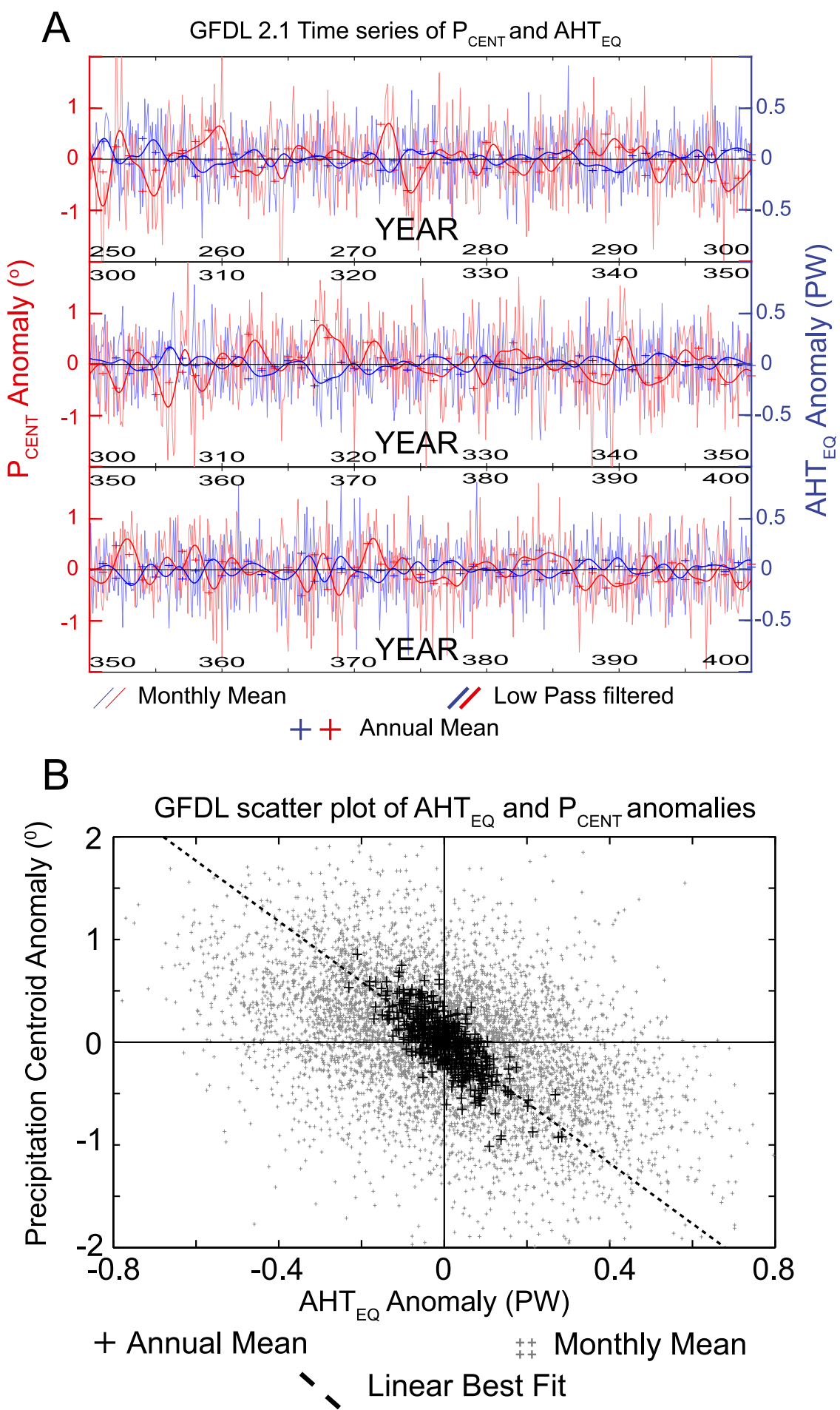

FIG. 4. (a) Time series of ITCZ location anomaly - as measured by the $P_{\text {CENT }}$ (blue) - and the anomaly in atmospheric heat transport at the equator (red) in the GFDL CM2.1 preindustrial simulation. The thin lines are the monthly-mean anomalies and the thick lines are the low-pass filtered time series (cutoff period of $2 \mathrm{yr}$ ). The thick crosses are the annual-mean anomalies from the climatology. Only years 250-400 of the 500-yr simulation are shown. (b) Scatterplot of the anomalies in $P_{\mathrm{CENT}}$ and $\mathrm{AHT}_{\mathrm{EQ}}$. The small gray crosses are the monthly means, and the thick black crosses are the annual means. The dashed black line is the linear best fit to the annual-mean data. 


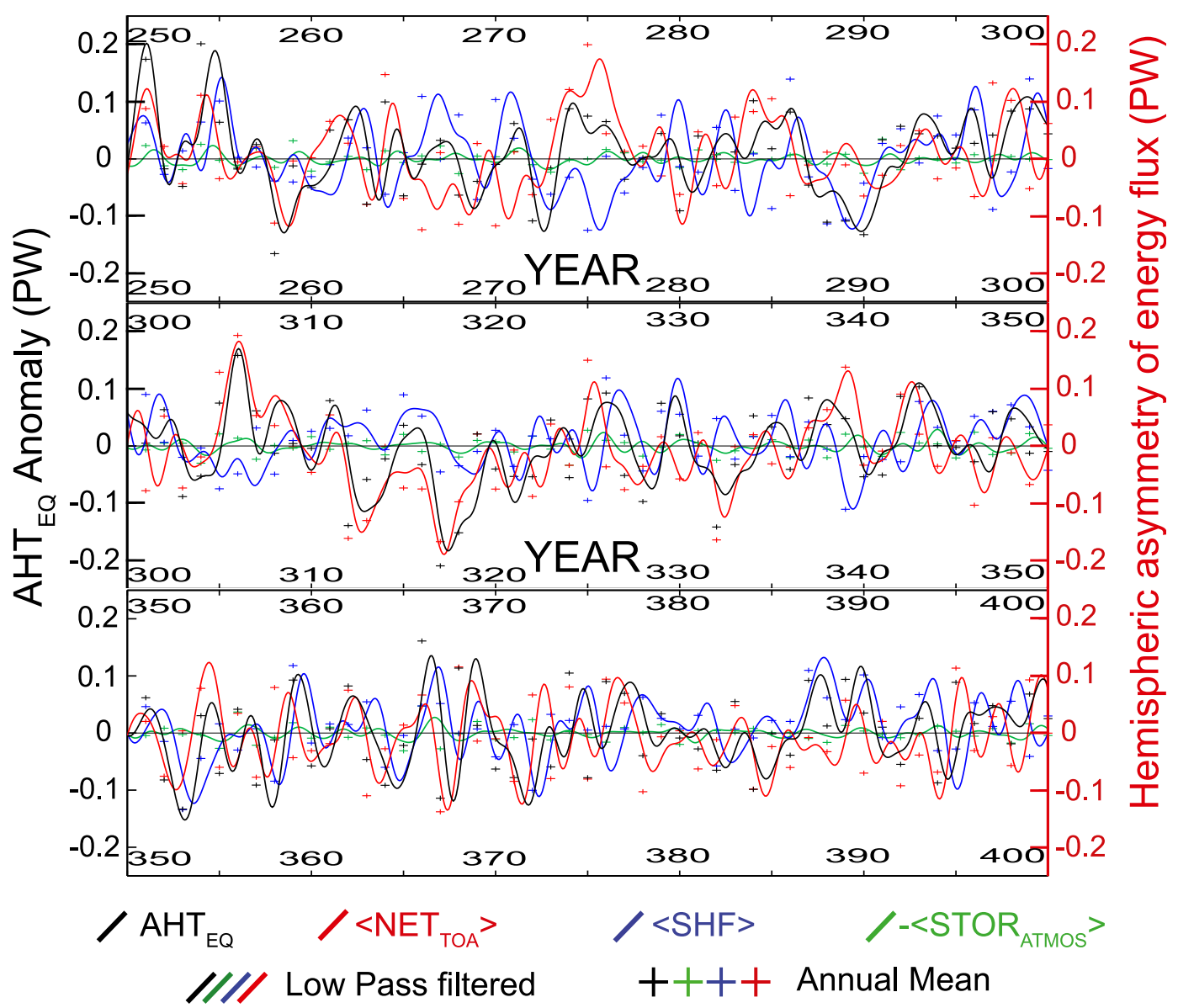

FIG. 5. Time series of the $\mathrm{AHT}_{\mathrm{EQ}}$ in the GFDL CM2.1 preindustrial simulation and its decomposition into the hemispheric asymmetry of TOA radiation ( $\left\langle\mathrm{NET}_{\mathrm{RAD}, \mathrm{TOA}}\right\rangle$, red), surface energy fluxes ( $\langle\mathrm{SHF}\rangle$, blue), and storage in the atmospheric column ( $\left\langle\mathrm{STOR}_{\mathrm{atmos}}\right\rangle$, green) from Eq. (2). The thick lines are the low-pass filtered time series (cutoff period of $2 \mathrm{yr}$ ). The thick crosses are the annual-mean anomalies from the climatology. Only years $250-400$ of the 500-yr simulation are shown.

GFDL CM2.1 model is associated with anomalous atmospheric energy transport between the two hemispheres. The latter interhemispheric energy flow in the atmosphere must be balanced by an interhemispheric contrast in atmospheric heating either by the radiative fluxes at the TOA or by the surface energy fluxes. More formally, $\mathrm{AHT}_{\mathrm{EQ}}$ can be expressed as the hemispheric asymmetry of energy fluxes to the atmosphere (and energy storage in the atmospheric column):

$$
\mathrm{AHT}_{\mathrm{EQ}}=\left\langle\mathrm{NET}_{\mathrm{RAD}, \mathrm{TOA}}\right\rangle+\langle\mathrm{SHF}\rangle-\left\langle\mathrm{STOR}_{\mathrm{atmos}}\right\rangle,
$$

where \langle\rangle brackets denote the difference between (spatially integrated) SH-mean and global-mean values. All fluxes are defined as positive when energy is fluxed to the atmosphere; $\mathrm{AHT}_{\mathrm{EQ}}$ is positive when the heat is transported northward across the equator, corresponding to a stronger heating of the $\mathrm{SH}$ than the $\mathrm{NH}$. The $\left\langle\mathrm{NET}_{\mathrm{RAD}, \mathrm{TOA}}\right\rangle$ is the net radiative heating of the $\mathrm{SH}$ at the TOA (minus the global-mean radiative imbalance) that is equivalent to the net radiative cooling of the $\mathrm{NH}$. The term $\langle\mathrm{SHF}\rangle$ is the net heating of the SH by upward energy fluxes (turbulent and radiative) from the surface to the atmosphere. The $\langle\mathrm{SHF}\rangle$ includes the combined effects of ocean energy transport and energy storage in the ocean. In equilibrium (i.e., no ocean energy storage), $\langle\mathrm{SHF}\rangle$ is equal (but of opposite sign) to the northward ocean heat transport across the equator $\left(\mathrm{OHT}_{\mathrm{EQ}}\right)$ : southward $\mathrm{OHT}_{\mathrm{EQ}}$ must be balanced by an export of energy from the atmosphere to the surface in the $\mathrm{NH}$ and an import of energy to the atmosphere from the ocean in the SH. On the interannual time scale, the hemispheric asymmetry of oceanic energy storage contributes to $\langle\mathrm{SHF}\rangle$ with preferential oceanic energy 
A

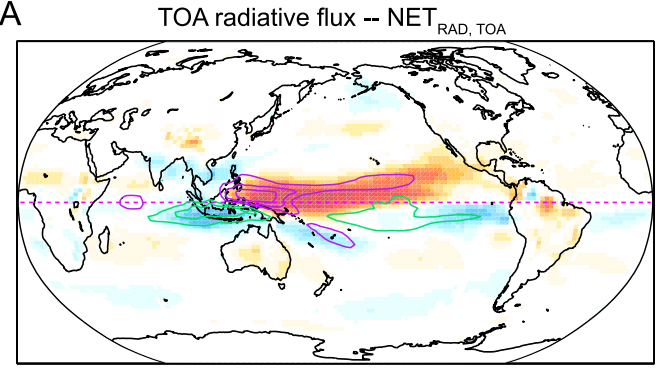

Positive precipitation anomaly $(2 \mathrm{~mm} /$ day contour $)$ Negative precipitation anomaly

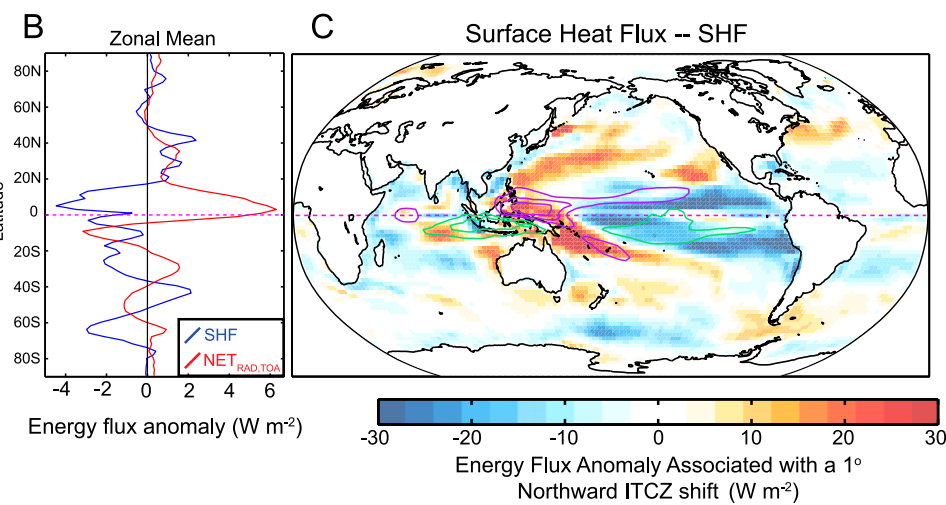

Northward ITCZ shift $\left(\mathrm{W} \mathrm{m}^{-2}\right)$

FIG. 6. Regression maps of (a) TOA radiative anomaly and (c) surface heat flux anomaly associated with a $-0.34-\mathrm{PW}$ AHT $\mathrm{EQ}$ annualmean anomaly that is the $\mathrm{AHT}_{\mathrm{EQ}}$ associated with a $1^{\circ}$ northward ITCZ shift in the GFDL preindustrial simulation. The energy fluxes are defined as positive when energy flows into the atmosphere (positive downward at the TOA and positive upward at the surface). The contours are the associated precipitation anomaly (contour interval $2 \mathrm{~mm} \mathrm{day}^{-1}$ ) with green contours indicating a decrease in precipitation and purple contours indicating an increase in precipitation. (b) Zonal-mean anomalies of the TOA radiative fluxes (red) and surface fluxes (blue).

storage in the $\mathrm{NH}$, corresponding to a positive $\langle\mathrm{SHF}\rangle$ because the atmosphere must export energy to the ocean in the $\mathrm{NH}$. The term $\left\langle\mathrm{STOR}_{\mathrm{atmos}}\right\rangle$ is the hemispheric asymmetry of the atmospheric column-integrated energy (sensible plus latent) tendency and is positive when the temperature or humidity of the atmosphere is increasing in the $\mathrm{SH}$, which serves as a pseudosink of energy in the $\mathrm{SH}$ [note the negative sign in Eq. (2)].

The time series of $\mathrm{AHT}_{\mathrm{EO}}$ and its decomposition into the hemispheric asymmetry of energy fluxes to the atmosphere via Eq. (2) are shown in Fig. 5. The interannual variability of $\mathrm{AHT}_{\mathrm{EQ}}$ has a standard deviation of $\sigma=$ $0.08 \mathrm{PW}$. The interannual variability of $\left\langle\mathrm{NET}_{\mathrm{RAD}, \mathrm{TOA}}\right\rangle$ $(\sigma=0.073 \mathrm{PW})$ is slightly larger but comparable in magnitude to that of $\langle\mathrm{SHF}\rangle(\sigma=0.058 \mathrm{PW})$. The interannual variability of the atmospheric energy storage $\left(\left\langle\mathrm{STOR}_{\mathrm{atmos}}\right\rangle\right)$ makes a smaller contribution to interannual variability of the hemispheric energy budget $(\sigma=0.017 \mathrm{PW})$ than the TOA and surface energy fluxes. Over the 450-yr simulation (see Fig. 5), anomalies in $\mathrm{AHT}_{\mathrm{EQ}}$ (black lines) are most strongly correlated with anomalies in $\left\langle\mathrm{NET}_{\mathrm{RAD}, \mathrm{TOA}}\right\rangle(R=0.67$, red lines $)$ and are less strongly correlated with anomalies in $\langle\mathrm{SHF}\rangle$ ( $R=0.30$, blue lines). The lead and lag relationships among $P_{\mathrm{CENT}}, \mathrm{AHT}_{\mathrm{EQ}},\left\langle\mathrm{NET}_{\mathrm{RAD}, \mathrm{TOA}}\right\rangle$, and $\langle\mathrm{SHF}\rangle$ are calculated from the low-pass filtered time series using a cutoff period of $2 \mathrm{yr}$. On average, $P_{\mathrm{CENT}}$ anomalies lead $\mathrm{AHT}_{\mathrm{EQ}}$ of the opposite sign by 3 months, as deduced from the time lag of optimal negative correlation. The hemispheric asymmetry of net radiation at the TOA $\left(\left\langle\mathrm{NET}_{\mathrm{RAD}, \mathrm{TOA}}\right\rangle\right)$ is in phase with $P_{\mathrm{CENT}}$ and leads the $\mathrm{AHT}_{\mathrm{EQ}}$; optimal lagged correlations occur for $\left\langle\mathrm{NET}_{\mathrm{RAD}, \mathrm{TOA}}\right\rangle$, leading $\mathrm{AHT}_{\mathrm{EQ}}$ by 3 months with a correlation of 0.69 . In contrast, the hemispheric asymmetry of surface energy fluxes $(\langle\mathrm{SHF}\rangle)$ lag the $\mathrm{AHT}_{\mathrm{EQ}}$ on average; optimal lagged correlations occur for $\langle\mathrm{SHF}\rangle$ lagging $\mathrm{AHT}_{\mathrm{EQ}}$ by 3 months with a correlation of 0.49 . The lead-lag relationships discussed above are qualitatively consistent over all 100-yr subsets of the simulation. Collectively, these results suggest that the interannual variability of $\mathrm{AHT}_{\mathrm{EO}}$, and thus the ITCZ location, is primarily a consequence of interannual variations in radiation at the TOA in the GFDL model, although it is unclear if the radiation anomaly is itself a manifestation of the ITCZ shift or forces the ITCZ shift.

We now ask, what regions contribute to the hemispheric asymmetries in energy fluxes for a "typical" $P_{\text {CENT }}$ anomaly? Figure 6 shows the regression of the interannual variability of $\mathrm{AHT}_{\mathrm{EQ}}$ onto the anomalies of the net radiative flux at the TOA (left panel) and surface fluxes (right panel) normalized to a $-0.34-\mathrm{PW} \mathrm{AHT}_{\mathrm{EQ}}$ anomaly, which corresponds to a $1^{\circ}$ northward ITCZ shift. The energy fluxes are defined as positive when energy flows into the atmosphere. The TOA radiative flux associated with the southward $\mathrm{AHT}_{\mathrm{EQ}}$ anomaly is positive in the tropical Pacific just north of the equator where the precipitation and cloud cover have increased concurrently with the northward shift of the ITCZ (the increased precipitation is indicated with the purple contours). In this region, the enhanced cloud cover results in less absorbed shortwave radiation (more reflection off the clouds) and reduced emitted longwave radiation as the outgoing longwave radiation (OLR) is emitted from higher in the atmospheric column where temperatures are colder (not shown). The magnitude of the reduced OLR (an energy gain) is larger than that of the reduced absorbed shortwave radiation (energy loss). Thus, shifting the ITCZ to the north results in 
atmospheric heating in the $\mathrm{NH}$ and cooling in the $\mathrm{SH}$ due to the net radiative cloud response. This mechanism acts as a positive feedback on ITCZ migration as the enhanced heating in the hemisphere, to which the ITCZ has shifted, requires that additional energy be fluxed to the other hemisphere, which is most readily accomplished by shifting the Hadley cell in the same sense of the initial perturbation. Thus, the local TOA radiation change associated with an ITCZ shift demands a crossequatorial atmospheric heat transport that shifts the Hadley cell in the same direction as the initial perturbation. We note that the radiative anomalies are primarily confined to the tropics and are manifestations of the ITCZ shift itself; extratropical radiative forcing does not play a prominent role in forcing interannual variations in $\mathrm{AHT}_{\mathrm{EQ}}$ in the GFDL model, which is a stark contrast to the role of extratropical cloud radiative forcing in the climatological response of the ITCZ to anthropogenic forcing (Frierson and Hwang 2012).

The surface heat flux anomaly associated with a northward $P_{\text {CENT }}$ shift is also dominated by a tropical signal with anomalous energy fluxes into the ocean in the eastern Pacific and anomalous energy fluxes to the atmosphere over a smaller region in the far western Pacific (Fig. 6c). The surface heat flux anomaly that accompanies the northward ITCZ shift is more symmetric about the equator than its TOA radiation counterpart (cf. the red and blue zonal mean in Fig. 6b). We will show in the following section that the interannual variability of ocean energy fluxes and storage in the deep tropics are of order $100 \mathrm{~W} \mathrm{~m}^{-2}$ and nearly compensating; the interannual variability of the upward surface heat flux is the small residual of large variations in the ocean energy transport divergence and the storage of energy within the oceanic column. As a result, the atmospheric and oceanic meridional energy transports do not compensate for one another on the interannual time scale because the vast majority of the ocean energy transport anomalies are stored locally in the ocean and therefore never impact the atmospheric energy budget.

\section{c. The role of interannual variability in ocean circulation on the hemispheric energy budget}

We now explore the role of interannual variability in the strength of the ocean circulation on the interannual variability of $\mathrm{AHT}_{\mathrm{EQ}}$ and therefore $P_{\mathrm{CENT}}$. Previous studies (Marshall et al. 2014; Frierson et al. 2013) have demonstrated that the approximately $0.7 \mathrm{PW}$ of northward energy transport of the AMOC across the equator (Ganachaud and Wunsch 2003) is the cause of the annualmean position of the ITCZ north of the equator. Previous studies have linked the multidecadal variability of the AMOC with large-scale precipitation anomalies (Zhang

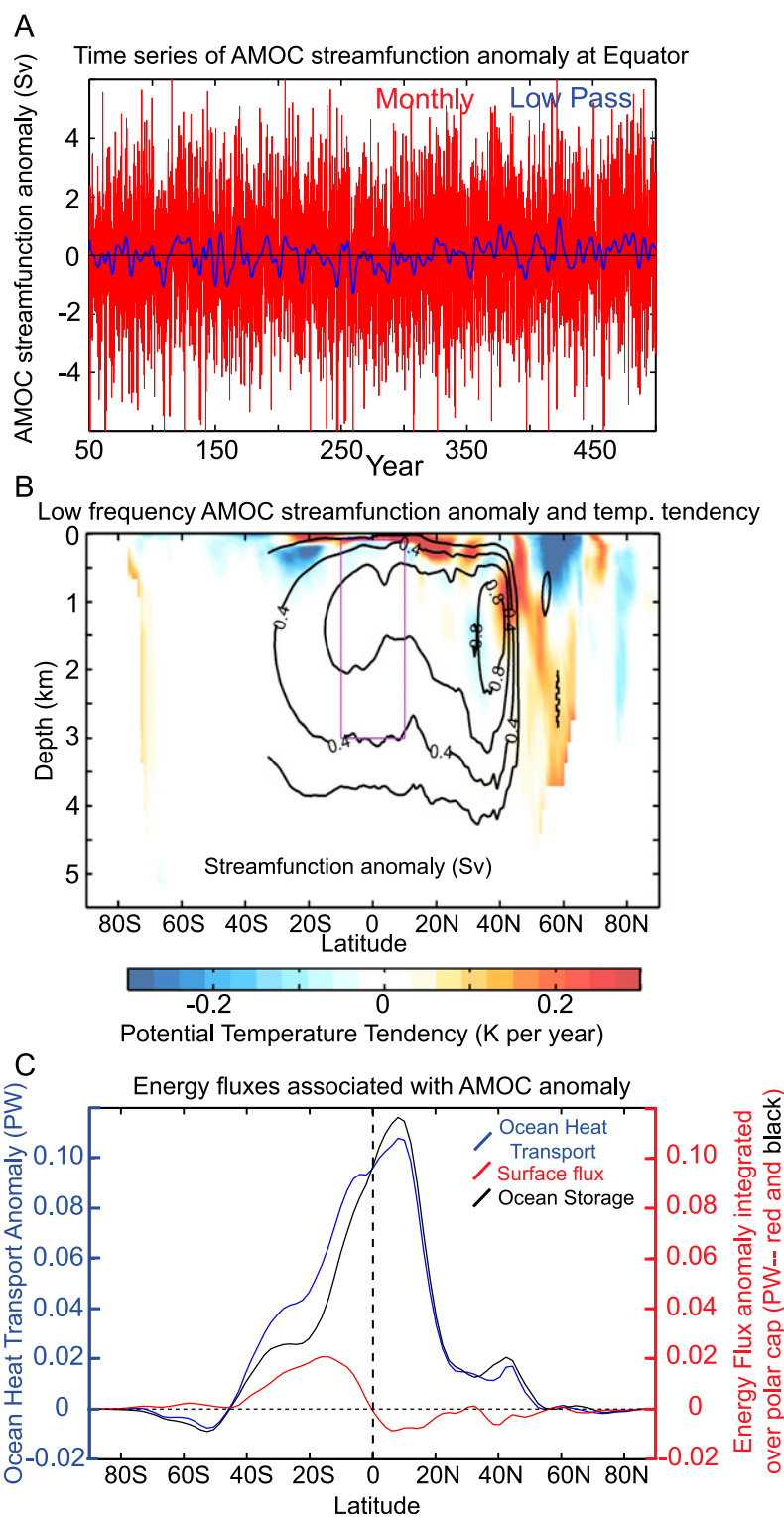

FIG. 7. (a) Time series of AMOC index, defined as the streamfunction anomaly averaged between 100- and 300-m depth and between $10^{\circ} \mathrm{S}$ and $10^{\circ} \mathrm{N}$. The red lines are the monthly means and the blue lines are the low-pass filtered time series using a cutoff period of $6 \mathrm{yr}$. (b) The contours show the cross section of low-pass AMOC index regressed onto AMOC streamfunction anomaly in Sv. The colored field is the associated temperature tendency in units of kelvins per year. The purple box shows the region used to define the AMOC index. (c) The ocean meridional heat transport anomaly associated with a one standard deviation AMOC event (blue line). The red line is the spatial integral of the surface heat flux (positive to the atmosphere) integrated over the polar cap north of a given latitude, and the black line is the storage in the ocean integrated over the polar cap. By construction, the surface flux (red) and the storage (black) sum to the ocean heat transport into the polar cap (blue). The results have been integrated over all ocean basins. 
and Delworth 2006). Tulloch and Marshall (2012) demonstrated that the AMOC in the GFDL CM2.1 model varies interannually by approximately $15 \%$ of the climatological-mean value (i.e., $\mathrm{AMOC} \mathrm{OHT}_{\mathrm{EQ}}$ varies on the order of $0.1 \mathrm{PW}$ ). Yet, we did not see a manifestation of the interannual variability of the AMOC in the surface heat fluxes leading to an $\mathrm{AHT}_{\mathrm{EQ}}$ anomaly (Fig. 6c). In this section, we ask why the interannual variability in the ocean heat transport across the equator is not accompanied by a compensating atmospheric heat transport across the equator.

We define an index of the variability of the AMOC by averaging the monthly anomaly (from climatology) of the AMOC streamfunction between 100 and $3000 \mathrm{~m}$ and between $10^{\circ} \mathrm{S}$ and $10^{\circ} \mathrm{N}$ (the region inside the purple box in Fig. 7b). A time series of the AMOC index (Fig. 7a) demonstrates that the AMOC at the equator varies by approximately $2.0 \mathrm{~Sv}\left(1 \mathrm{~Sv} \equiv 10^{6} \mathrm{~m}^{3} \mathrm{~s}^{-1}\right)(1 \sigma)$ from month to month, which is approximately $20 \%$ of the climatological-mean value of $10.6 \mathrm{~Sv}$. The interannual variability of the AMOC index explains the majority $(R=0.82)$ of the ocean heat transport anomalies across the equator in the Atlantic (not shown). The AMOC index has very little memory from month to month; the decorrelation time scale is less than 1 month. This shortterm variability in the AMOC is primarily due to the shallow Ekman transport anomalies associated with the zonal wind stress anomalies; the accompanying energy flux anomalies are nearly entirely stored locally in the ocean and never impact the atmospheric column. For this reason, we choose to focus on the lower-frequency variability of the AMOC that we define using a low-pass Butterworth filter with a cutoff period of $6 \mathrm{yr}$ (blue line in Fig. 7a). ${ }^{5}$ Much of the low-frequency variability of the AMOC in the GFDL model is at the decadal frequency (Tulloch and Marshall 2012). The low-frequency AMOC index has an amplitude of approximately $25 \%$ of that in monthly data. The cross section of AMOC streamfunction anomalies associated with a $1 \sigma$ lowfrequency AMOC index anomaly (Fig. 7b) demonstrates that the low-frequency AMOC anomalies are strongly correlated over the upper $3000 \mathrm{~m}$ of the column and from $20^{\circ} \mathrm{S}$ to $45^{\circ} \mathrm{N}$ with peak anomalies north of the equator.

The ocean heat transport anomalies must either be balanced by storage in the oceanic column (a change in potential temperature) or by upward surface energy fluxes to the atmosphere:

\footnotetext{
${ }^{5}$ Using a cutoff period of $2 \mathrm{yr}$, as in the previous section, produces qualitatively similar results.
}

$$
\nabla \cdot \mathrm{OHT}=\mathrm{SHF}+\mathrm{STOR}_{\mathrm{OCEAN}} \cdot
$$

We calculate the energy storage in the oceanic column $\left(\mathrm{STOR}_{\mathrm{OCEAN}}\right)$ as the tendency (centered finite difference) of the mass integral of $C_{P \text {,ocean }} \Theta$, where $C_{P \text {,ocean }}$ is the heat capacity of ocean water and $\Theta$ is the potential temperature. The surface heat flux (SHF; positive to the atmosphere) is directly outputted on the ocean grid. The value $\nabla \cdot$ OHT is calculated as the residual of Eq. (3). The ocean heat transport anomaly is calculated as the spatial integral of $\boldsymbol{\nabla}$. OHT over the polar cap poleward of each latitude.

The ocean heat transport anomaly associated with the AMOC anomaly (Fig. 7c) shows the expected northward heat transport anomaly at the equator of order $0.1 \mathrm{PW}$. We note that approximately half of this ocean heat transport anomaly is associated with the Atlantic basin with maximum ocean heat transport convergence in the midlatitude (Fig. 8b), and the remainder is due to the ocean circulation changes in the Pacific where the heat transport convergence occurs in the subtropics. The approximately $0.05 \mathrm{PW}$ of northward heat transport associated with the 0.5-Sv AMOC index anomaly corresponds to a potential temperature difference of $25 \mathrm{~K}$ between the anomalous northward flow at the surface and the southward return flow at the depth that is consistent with the ocean's static stability in the tropics in the model. By construction, the ocean heat transport across a given latitude circle is balanced by the sum of the spatial integrals of SHF and STOR over the polar cap north of that latitude (i.e., the black and red lines in Fig. 7 sum to the blue line). By and large, the anomalous ocean heat transport associated with an AMOC index anomaly is balanced by ocean heat storage poleward of the energy flux anomaly and only secondarily by fluxes to the atmosphere. More specifically, the $0.10 \mathrm{PW}$ of anomalous northward ocean heat transport at the equator goes entirely into ocean energy storage and never gets fluxed upward to the atmosphere. As a consequence, the atmospheric energy budget is unaffected by the ocean heat transport anomaly; there is no compensating atmospheric heat transport to the ocean heat transport anomaly, and thus the tropical precipitation is unaffected by the AMOC anomaly. There is no significant correlation between the AMOC index and $\mathrm{AHT}_{\mathrm{EQ}}$ or $P_{\mathrm{CENT}}$, even when lagged correlations are considered and when AMOC anomalies at different latitudes are considered. This conclusion also holds when considering the decadal variability of the AMOC (i.e., using a 20 -yr period lowpass filter).

The spatial maps of anomalous $\boldsymbol{\nabla}$. OHT associated with a $1 \sigma$ AMOC index (Fig. 8) and its allocation 
A Zonal Mean - All Basins

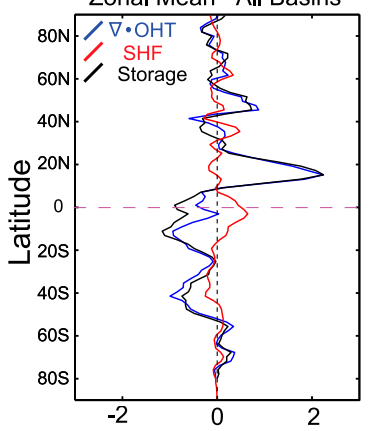

Energy flux anomaly $\left(\mathrm{W} \mathrm{m}^{-2}\right)$
B Ocean Heat Transport Convergence

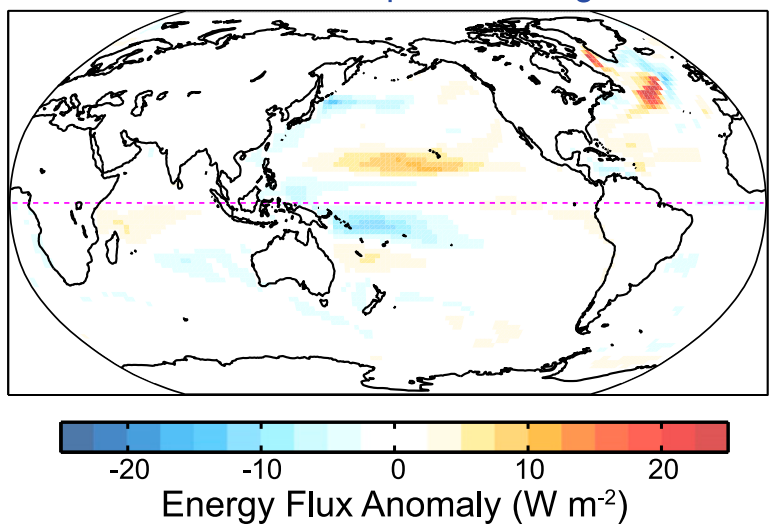

C Zonal Mean-- Atlantic

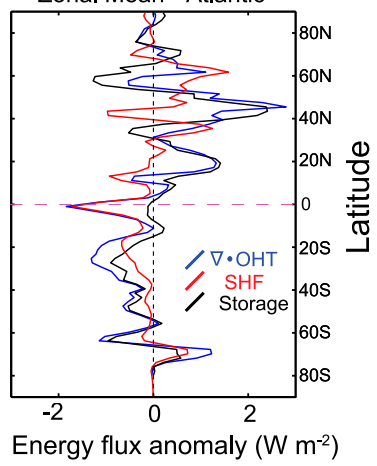

D

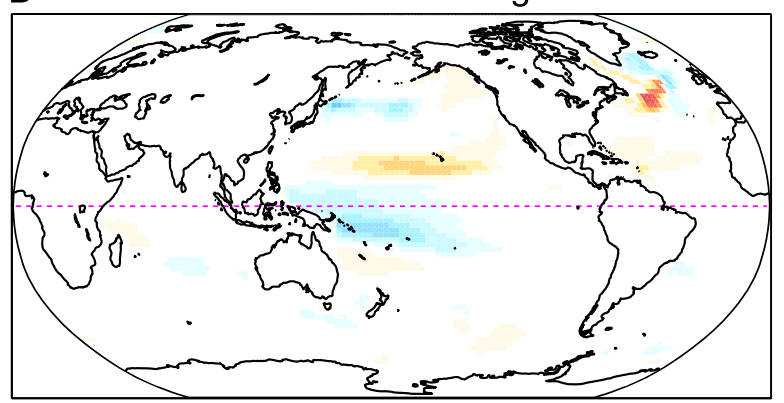

E Surface Heat Flux (SHF-- to the atmosphere)

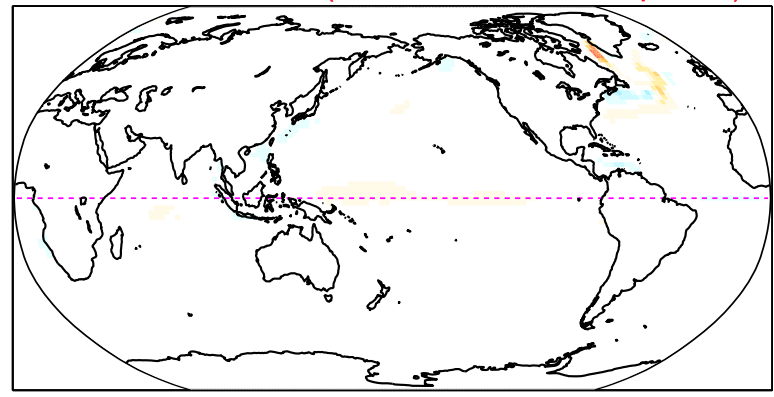

FIG. 8. Spatial maps of anomalies in (b) ocean heat transport convergence, (d) column-integrated ocean heat content tendency (ocean heat storage), and (e) surface heat flux to the atmosphere associated with a one standard deviation in AMOC index. (a) The zonal means of the anomalies in the ocean heat transport convergence (blue), ocean heat storage (black), and surface heat flux to the atmosphere (red). (c) The zonal mean over the Atlantic basin only.

between SHF and STOR $_{\text {ocean }}$ show that the vast majority of the anomalous $\boldsymbol{\nabla}$. OHT is in the extratropical North Atlantic. The anomalous ocean heat transport convergence in the North Atlantic is balanced by local storage as opposed to surface energy fluxes out of the ocean (cf. Figs. 8d and 8e). The SHF anomaly associated with an AMOC index anomaly is smaller in magnitude than the corresponding ocean heat storage anomaly and features a dipole in the vicinity of the Gulf Stream. We speculate that this anomalous SHF is associated with a concurrent shift in the Gulf Stream and is not related to the ocean heat transport anomaly in the AMOC.

We now ask why does not the interannual variability of the AMOC energy transport (on the order of $0.1 \mathrm{PW}$ ) impact the atmospheric energy budget by way of the surface energy fluxes? The most obvious explanation is that the ocean heat transport anomalies are converged deep within the oceanic column and therefore do not impact the SSTs and surface energy fluxes. Indeed, the vertical profile of oceanic temperature tendencies associated with an AMOC index anomaly (colored field in
Fig. 7b) show that, in the region of anomalous AMOC energy flux convergence, around $50^{\circ} \mathrm{N}$, the heating occurs primarily below the ocean mixed layer and extends all the way down to $4-\mathrm{km}$ depth. At the surface, the anomalously strong AMOC causes cooling in the vicinity of $60^{\circ} \mathrm{N}$ and a slight warming in the deep tropics; there is only a hint of surface warming in the northern extratropics due to the AMOC anomaly (over the limited region around $45^{\circ} \mathrm{N}$ ). The SST anomaly associated with a one standard deviation AMOC index shows slight warming $(\sim 0.2 \mathrm{~K})$ over a limited domain poleward of $45^{\circ} \mathrm{N}$ (not shown). Overall, the canonical view of AMOC anomalies influencing the extratropical climate system in the North Atlantic is unrealized in the interannual variability of the GFDL model because the AMOC anomalies only influence ocean temperatures at depth.

\section{Summary and discussion}

Previous work has demonstrated that the relationship between ITCZ location and atmospheric heat transport across the equator is quantitatively consistent across 
a myriad of time scales ranging from the seasonal cycle to the annual-mean climatology and shift due to the external forcing. The dominant physical processes contributing to the $\mathrm{AHT}_{\mathrm{EQ}}$ by way of the hemispheric asymmetry of energy input into the atmosphere vary with time scale. In the annual-mean climatology, the hemispheric asymmetry of atmospheric heating is dominated by the upward surface heat fluxes by way of the ocean heat transport across the equator (Marshall et al. 2014). On decadal and shorter time scales, the anomalies in the ocean heat transport and radiative energy input into the surface are stored within the ocean column and thus do not contribute to the atmospheric energy budget. Indeed, over the seasonal cycle variations in $\mathrm{AHT}_{\mathrm{EQ}}$ are driven by the absorption of insolation in the atmospheric column (Donohoe et al. 2013) and opposed by the surface fluxes as the ocean energy storage in the summer hemisphere exceeds the input of energy into the surface by radiative process and ocean heat transport convergence (Donohoe and Battisti 2013). Here, we focus on an intermediate time scale: the interannual (2$10 \mathrm{yr})$ variability.

We demonstrate that the interannual variability of ITCZ location and $\mathrm{AHT}_{\mathrm{EQ}}$ are strongly (negatively) correlated in nature $(R=-0.75)$ and a coupled climate model $(R=-0.76)$. A $1^{\circ}$ northward ITCZ shift is associated with approximately $-0.33 \mathrm{PW}$ of southward $\mathrm{AHT}_{\mathrm{EQ}}$ that is statistically indistinguishable from the relationship found over the seasonal cycle and the annual-mean response due to the external climate forcing (Donohoe et al. 2013). The interannual variability of $\mathrm{AHT}_{\mathrm{EQ}}$ and ITCZ location both reflect a mutual connection to an intensification of the climatological Hadley cell and the concurrent intensification of the climatological precipitation maximum (Fig. 3). The cause of the interannual variability on $\mathrm{AHT}_{\mathrm{EQ}}$ by way of the hemispheric scale atmospheric energy budget is diagnosed in the climate model (such analysis is not possible in the observations). The interannual variability of $\mathrm{AHT}_{\mathrm{EQ}}$ is primarily due to the hemispheric asymmetries in radiative fluxes at the TOA, but also due to the surface energy fluxes and has a weak dependence on atmospheric energy storage (Fig. 5). The radiative flux anomalies associated with a northward ITCZ shift are primarily a consequence of the ITCZ shift itself with more intense deep convection north of equator resulting in a net radiative heating anomaly in the $\mathrm{NH}$ (Fig. 6). The increased convection north of the equator causes reduced OLR as radiation is emitted from higher in the atmospheric column (due to both water vapor and cloud feedbacks) where the air is colder. The absorbed shortwave radiation also decreases north of the equator due to the increased cloud reflection. In the net, the OLR feedback is stronger

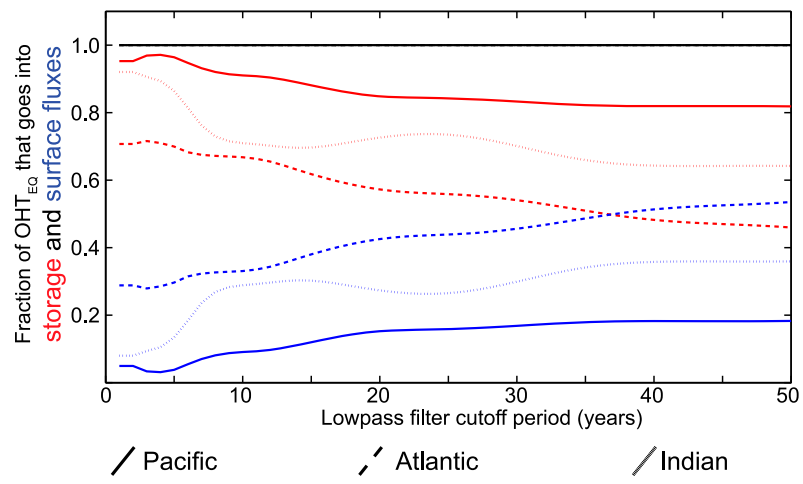

FIG. 9. The fraction of $\mathrm{OHT}_{\mathrm{EQ}}$ that get stored in the ocean column (red) and fluxed upward to the atmosphere (blue) over the spatial integral of the polar cap as a function of low-pass filter cutoff period. The solid line is for the Pacific basin. The horizontally hashed line is for the Atlantic, and the vertically hashed line is for the Indian Ocean.

in magnitude. As a result, a northward-shifted ITCZ results in stronger atmospheric heating in the $\mathrm{NH}$ that serves as a positive feedback for ITCZ migration; the Hadley cell shift required to achieve the $\mathrm{AHT}_{\mathrm{EQ}}$ demanded by the global-scale TOA radiative budget shifts the ITCZ in the same sense as the initial perturbation. We note that this conclusion may be model dependent (Voigt et al. 2014), and we have only demonstrated the net positive radiative feedback in the GFDL CM2.1 model.

A determination of the energetic source of interannual variability of $\mathrm{AHT}_{\mathrm{EQ}}$ in nature is limited by our observations of both the TOA radiation and the surface energy fluxes; the observed atmospheric energy budget is not closed on the interannual time scale. In the globalmean climatology, the TOA energy budget is not closed to within $5 \mathrm{~W} \mathrm{~m}^{-2}$ (Loeb et al. 2009). How these observational uncertainties project onto hemispheric asymmetries of energy input to the atmosphere at the interannual time scale is unclear. TOA radiative anomalies from CERES EBAF are available for the 2001-12 time period and could provide insights about whether the processes responsible for the interannual variability of $\mathrm{AHT}_{\mathrm{EQ}}$ in the GFDL model are also realized in the observations. Preliminary work suggests that radiative feedbacks explain a significant portion of the interannual variability of $\mathrm{AHT}_{\mathrm{EQ}}$ and that the ITCZ shift induces a positive radiative feedback on the atmospheric heating (warming the hemisphere that the ITCZ has shifted toward).

Why does not the interannual variability of ocean heat transport have an impact on ITCZ location? Indeed, the interannual variability of the AMOC ocean heat transport across the equator $(\sim 0.1 \mathrm{PW})$ is comparable in 
magnitude to the interannual variability of $\mathrm{AHT}_{\mathrm{EQ}}(\sigma=$ $0.08 \mathrm{PW}$ ) in the GFDL CM2.1 model. However, the latter is not influenced by the former. The reason the AMOC (and the ocean heat transport across the equator in general) does not influence the atmosphere on the interannual time scale is that the vast majority of AMOC heat transport anomalies are stored within the ocean, below the surface (Fig. 7) and thus do not enter the atmospheric column (Fig. 8e). Similar results are found when considering the decadal variability of the AMOC that has been shown to be significant and predictable in this model (Tulloch and Marshall 2012). This result suggests that the interannual variability of ocean circulation plays a negligible role in the interannual variability of atmospheric energy fluxes because the latter is dominated by TOA radiative fluxes that are very sensitive to even modest changes in clouds.

The impact of ocean heat transport on the atmospheric circulation varies drastically with time scale (Fig. 9). On short time scales (from years to decades), energy is stored in the oceanic column, has a small expression on SSTs, and very little energy gets fluxed upward to the atmosphere to impact the atmospheric circulation (the red (storage) lines have larger magnitudes than the blue (surface flux) lines on the highfrequency side of Fig. 9). On very long time scales (climatology), the surface energy budget requires that the entirety of the ocean heat transport convergence be fluxed upward to the atmosphere and is thus the dominant mechanism of the hemispheric contrast of energy input to the atmosphere. At what time scale, then, does the ocean heat transport impact the hemispheric-scale atmospheric energy budget and thus the ITCZ position? In the GFDL CM2.1 model, half of the $\mathrm{OHT}_{\mathrm{EQ}}$ is fluxed upward to the atmosphere at a time scale of $35 \mathrm{yr}$ in the Atlantic (where the dashed red and blue line cross in Fig. 9), whereas the same time scale is longer in the other ocean basins. This result suggests that the AMOC may impact the atmospheric energy budget and thus the ITCZ at the multidecadal frequency as was found by Zhang and Delworth (2006).

The positive feedback between ITCZ shifts and $\mathrm{AHT}_{\mathrm{EQ}}$ induced by the tropical cloud feedbacks in the GFDL model relies on the positive longwave cloud feedback associated with an increase in convective clouds in the tropics being larger in magnitude than the negative shortwave cloud feedback. It is unclear if this relationship is robust across different models and is evident in nature. Recent work by Voigt et al. (2014) suggests that tropical radiative feedbacks play a negligible role in determining the magnitude of the ITCZ shift in response to hemispheric-scale forcing in the ECHAM6 model, whereas Kang et al. (2008) previously found that cloud radiative feedbacks provide a negative feedback to ITCZ shifts. Preliminary analysis of the interannual variability of observations (CERES EBAF; Loeb et al. 2009) suggests that radiative anomalies provide a small net tropical heating anomaly $\left(\sim 1 \mathrm{~W} \mathrm{~m}^{-2}\right)$ to the hemisphere to which the ITCZ has shifted (not shown). In the GFDL model, tropical radiation anomalies (equatorward of $20^{\circ}$ ) associated with anomalous southward $\mathrm{AHT}_{\mathrm{EQ}}$ (Fig. 6) account for approximately half (45\%) of the hemispheric asymmetry of energy input to the atmosphere demanded by the $\mathrm{AHT}_{\mathrm{EQ}}$ anomaly. If we assume that the magnitude of tropical radiation anomalies is proportional to the $\mathrm{AHT}_{\mathrm{EQ}}$ (i.e., the magnitude of the ITCZ shift), this result suggests that tropical cloud feedbacks amplify the ITCZ shift due to the external forcing by a factor of 2; the ITCZ shift required to export a given energy input into the $\mathrm{NH}$ is twice as large when tropical radiative feedbacks are active as compared to a system with no tropical radiative feedbacks. More formally, the feedback gain of tropical radiative feedbacks can be shown to be approximately two, relative to a reference system with no tropical cloud feedbacks. We note that this result is at odds with the work of Voigt et al. (2014) that found little amplification of ITCZ shifts by radiative feedbacks in ECHAM6.

An alternative negative feedback to an ITCZ perturbation is that the wind-driven components of the oceanic and atmospheric energy transport are coupled via the surface wind stress (and Ekman dynamics) and transport energy in the same direction (Held 2001) in both the climatology and the anomalous sense. Therefore, if the system is externally forced by a hemispheric asymmetry of atmospheric heating, the anomalous $\mathrm{AHT}_{\mathrm{EQ}}$ and $\mathrm{OHT}_{\mathrm{EQ}}$ will be in the same direction with each fluid carrying comparable quantities of energy. On short time scales, the ocean heat transport anomaly is stored within the ocean, and the atmospheric energy budget is unaffected. On longer time scales, as the ocean heat storage decreases, the $\mathrm{OHT}_{\mathrm{EQ}}$ anomaly is fluxed upward to the atmosphere, and the hemispheric asymmetry of surface heat fluxes opposes the initial external forcing. In equilibrium, the interhemispheric energy flow demanded by the external forcing is achieved by the sum of the $\mathrm{AHT}_{\mathrm{EQ}}$ and $\mathrm{OHT}_{\mathrm{EQ}}$ that are in the same direction and comparable in magnitude. Therefore, the $\mathrm{AHT}_{\mathrm{EQ}}$ anomaly in an externally forced coupled (interactive ocean) system is significantly smaller than it is in the uncoupled system (atmosphere only). This mechanism is expected to decrease the sensitivity of ITCZ migration to external forcing that has been deduced from atmospheric-only simulations (i.e., Yoshimori and Broccoli 2008; Kang et al. 2008). 
We note that the interannual variability of $P_{\mathrm{CENT}}$ is also significantly correlated with the interhemispheric difference in tropical SSTs-defined as the difference between the spatially averaged SST between the equator and $20^{\circ} \mathrm{N}$ and that between the equator and $20^{\circ} \mathrm{S}$ (Donohoe et al. 2013) - in nature $(R=0.61)$ and in the coupled climate model $(R=0.69)$. This suggests that the ITCZ location, the atmospheric heat transport across the equator, and the tropical SSTs all adjust in concert such that the ITCZ is located in the warmer hemisphere where the atmosphere is heated more strongly. Though this relationship is self-consistent, there is an issue of causality: is the ITCZ location dictated by the SSTs or the hemispheric-scale energy budget? This work has focused on the connection between the hemispheric-scale energy budget and ITCZ location in an attempt to dissect the relative roles of radiation and surface heat fluxes in determining the interannual variability of $\mathrm{AHT}_{\mathrm{EQ}}$ and thus ITCZ location. While we find that radiative processes at the TOA play a more prominent role than surface fluxes in the hemispheric-scale energy budget at the interannual time scale, this conclusion is likely time scale dependent. At short time scales, the ocean heat transport and SSTs/surface energy fluxes are decoupled due to the ocean energy storage, while at longer time scales the ocean heat transport gives rise to SST anomalies and surface fluxes. Indeed, preliminary work indicates that at the multidecadal time scale the ITCZ location is well correlated with persistent SST anomalies that result from decadal variability in the ocean heat transport.

Acknowledgments. We thank Aiko Voigt and three anonymous reviewers for insightful comments and suggestions. AD was supported by the NOAA Global Change Postdoctoral Fellowship. KA was funded by the James S. McDonnell Foundation Postdoctoral Fellowship.

\section{REFERENCES}

Chiang, J., and C. Bitz, 2005: The influence of high latitude ice on the position of the marine intertropical convergence zone. Climate Dyn., 25, 477-496, doi:10.1007/s00382-005-0040-5.

Delworth, T. L., A. J. Broccoli, A. Rosati, R. J. Stouffer, V. Balaji, J. A. Beesley, and W. F. Cooke, 2006: GFDL's CM2 global coupled climate models. Part I: Formulation and simulation characteristics. J. Climate, 19, 643-674, doi:10.1175/ JCLI3629.1.

Donohoe, A., and D. Battisti, 2013: The seasonal cycle of atmospheric heating and temperature. J. Climate, 26, 4962-4980, doi:10.1175/JCLI-D-12-00713.1.

_ J. Marshall, D. Ferreira, and D. McGee, 2013: The relationship between ITCZ location and atmospheric heat transport across the equator: From the seasonal cycle to the
Last Glacial Maximum. J. Climate, 26, 3597-3618, doi:10.1175/ JCLI-D-12-00467.1.

Frierson, D. M. W., and Y.-T. Hwang, 2012: Extratropical influence on ITCZ shifts in slab ocean simulations of global warming. J. Climate, 25, 720-733, doi:10.1175/ JCLI-D-11-00116.1.

_ , and Coauthors, 2013: Contribution of ocean overturning circulation to tropical rainfall peak in the Northern Hemisphere. Nat. Geosci., 6, 940-944, doi:10.1038/ngeo1987.

Ganachaud, A., and C. Wunsch, 2003: Large-scale ocean heat and freshwater transports during the World Ocean Circulation Experiment. J. Climate, 16, 696-705, doi:10.1175/ 1520-0442(2003)016<0696:LSOHAF $>2.0 . \mathrm{CO} ; 2$.

Griffies, S., and Coauthors, 2005: Formulation of an ocean model for global climate simulations. Ocean Sci., 1, 45-79, doi:10.5194/ os-1-45-2005.

Hadley, G., 1735: Concerning the cause of the general trade-winds. Philos. Trans., 39, 58-62, doi:10.1098/rstl.1735.0014.

Held, I., 2001: The partitioning of the poleward energy transport between the tropical ocean and atmosphere. J. Atmos. Sci., 58, 943-948, doi:10.1175/1520-0469(2001)058<0943: TPOTPE $>2.0 . \mathrm{CO} ; 2$.

Kalnay, E., and Coauthors, 1996: The NCEP/NCAR 40-Year Reanalysis Project. Bull. Amer. Meteor. Soc., 77, 437-471, doi:10.1175/1520-0477(1996)077<0437:TNYRP>2.0.CO;2.

Kang, S., I. Held, D. Frierson, and M. Zhao, 2008: The response of the ITCZ to extratropical thermal forcing: Idealized slabocean experiments with a GCM. J. Climate, 21, 3521-3532, doi:10.1175/2007JCLI2146.1.

Lin, S. J., 2004: A "vertically Lagrangian" finite-volume dynamical core for global models. Mon. Wea. Rev., 132, 2293-2307, doi:10.1175/1520-0493(2004)132<2293:AVLFDC>2.0.CO;2.

Loeb, N. G., B. A. Wielicki, D. R. Doelling, G. L. Smith, D. F. Keyes, S. Kato, N. Manalo-Smith, and T. Wong, 2009: Towards optimal closure of the earth's top-of-atmosphere radiation budget. J. Climate, 22, 748-766, doi:10.1175/ 2008JCLI2637.1.

Lorenz, E., 1953: A multiple-index notation for describing atmospheric transport processes. Geophys. Res. Pap., 24, 100-110. [Available online at http://eaps4.mit.edu/research/Lorenz/ A-Multiple-Index_Notation_1953.pdf.]

Marshall, J., A. Donohoe, D. Ferreira, and D. McGee, 2014: The ocean's role in setting the mean position of the intertropical convergence zone. Climate Dyn., 14, doi:10.1007/ s00382-013-1767-z, in press.

Priestley, C., 1949: Heat transport and zonal stress between latitudes. Quart. J. Roy. Meteor. Soc., 75, 28-40, doi:10.1002/ qj. 49707532307.

Trenberth, K. E., 1997: Using atmospheric budgets as a constraint on surface fluxes. J. Climate, 10, 2796-2809, doi:10.1175/ 1520-0442(1997)010<2796:UABAAC $>2.0 . \mathrm{CO} ; 2$.

_ , and J. M. Caron, 2001: The atmospheric energy budget and implications for surface fluxes and ocean heat transports. Climate Dyn., 17, 259-276, doi:10.1007/PL00007927.

Tulloch, R., and J. Marshall, 2012: Exploring mechanisms of variability and predictability of Atlantic meridional overturning circulation in two coupled climate models. J. Climate, 25, 4067-4080, doi:10.1175/JCLI-D-11-00460.1.

Voigt, A., B. Stevens, J. Bader, and T. Mauritsen, 2013: The observed hemispheric symmetry in reflected shortwave irradiance. J. Climate, 26, 468-477, doi:10.1175/JCLI-D-12-00132.1. - — - —, and — 2014: Compensation of hemispheric albedo asymmetries by shifts of the ITCZ and 
tropical clouds. J. Climate, 27, 1029-1045, doi:10.1175/ JCLI-D-13-00205.1.

Xie, P., and P. Arkin, 1996: Analyses of global monthly precipitation using gauge observations, satellite estimates, and numerical model predictions. J. Climate, 9, 840-858, doi:10.1175/ 1520-0442(1996)009<0840:AOGMPU>2.0.CO;2.

Yoshimori, M., and A. J. Broccoli, 2008: Equilibrium response of an atmosphere-mixed layer ocean model to different radiative forcing agents: Global and zonal mean response. J. Climate, 21, 4399-4423, doi:10.1175/2008JCLI2172.1.
— , and — 2009: On the link between Hadley circulation changes and radiative feedback processes. Geophys. Res. Lett., 36, L20703, doi:10.1029/2009GL040488.

Zhang, R., and T. Delworth, 2005: Simulated tropical response to a substantial weakening of the Atlantic thermohaline circulation. J. Climate, 18, 1853-1860, doi:10.1175/ JCLI3460.1.

- and - 2006: Impact of Atlantic multidecadal oscillations on India/Sahel rainfall and Atlantic hurricanes. Geophys. Res. Lett., 33, L17712, doi:10.1029/2006GL026267. 